\title{
Uso de metodologias ativas em programa de Residência em Saúde no contexto da pandemia por COVID-19
}

\author{
Jéssica Maria de Andrade Ventura ${ }^{1}$ \\ Alcieros Martins da Paz $^{2}$ \\ Mirela Dantas Ricarte ${ }^{3}$
}

\begin{abstract}
1 Mestranda em Educação para o Ensino na área da Saúde na Faculdade Pernambucana de Saúde (FPS). Cirurgiã-dentista graduada pela Faculdade de Odontologia de Pernambuco e egressa do Programa de Residência em Odontologia em Saúde Coletiva da Secretaria de Saúde do Recife - SESAU PE ${ }^{2}$ Coordenadora do Programa de Residência Multiprofissional em Saúde Coletiva - Secretaria de Saúde do Recife - PE. Professora assistente da Universidade de Pernambuco (UPE) e sanitarista da Prefeitura do Recife 3Professora Adjunta do Departamento de Psicologia da Universidade Federal do Piauí (UFPI). Doutora em Psicologia Cognitiva pela Universidade Federal de Pernambuco (UFPE). Psicóloga, com formação direcionada para avaliação de transtornos na infância. É membro do Núcleo de Estudos em Avaliação Psicológica (NEAP), vinculado ao Programa de Pós-Graduação em Psicologia Cognitiva (UFPE)
\end{abstract}

\section{RESUMO}

Introdução: $\mathrm{O}$ processo do ensino-aprendizagem tem passado por diversas modificações ao longo do tempo. O estudo sobre as Metodologias Ativas, consideradas ferramentas utilizadas como proposta alternativa ao contexto apenas transmissor no ensino-aprendizagem, tem sido realizada ao longo dos anos e encontra respaldo na ideia de contribuir para a discussão acadêmica de recursos didáticos usados. Em meio à pandemia da COVID 19 juntamente com o ensino online, o uso dessas ferramentas passou a ser mais intensificado. Objetivo: $\mathrm{O}$ presente trabalho objetivou caracterizar a percepção de residentes sobre o uso de metodologias ativas utilizadas em uma disciplina do Programa de Residência em Odontologia/ Saúde Coletiva da Secretaria de Saúde do Recife - PE realizada no formato online devido ao contexto da pandemia. Método: Foi realizada uma pesquisa quantitativa por meio de dados de origem qualitativa a partir do método de análise de conteúdo mediante o software Iramuteq. Conclusões: A percepção dos residentes com relação às metodologias ativas destacou a ferramenta como sendo muito mais interessante que o modelo tradicional na visão desses profissionais que também evidenciaram pontos como autonomia na participação das atividades, o espaço dialógico, os benefícios e desafios de trabalhar em equipe, além de ressaltar a discussão sobre a necessidade de preparação prévia e formação tanto por parte dos alunos quanto de facilitadores para o desenvolvimento das atividades.

Palavras-chave: Internato e Residência, Aprendizagem e Educação

Use of active methodologies in Health Residency program in the context of COVID-19 pandemic 


\begin{abstract}
Introduction: The teaching-learning process has undergone several changes over time. The study on Active Methodologies, considered tools used as an alternative proposal to the context that only transmits teaching and learning, has been carried out over the years and finds support in the idea of contributing to the academic discussion of didactic resources used. In the midst of the COVID 19 pandemic together with online education, the use of these tools has become more intensified. Objective: This study aimed to characterize the perception of residents about the use of active methodologies used in a discipline of the Residency Program in Dentistry in Public Health of the Secretariat of Health of Recife - PE carried out in the online format. Method: Quantitative research was carried out using data of qualitative origin using the content analysis method using the Iramutec software. Conclusions: The residents perception of active methodologies highlighted the tool as being much more interesting than the traditional model, highlighting points such as autonomy in the participation of activities, the dialogical space, the benefits and challenges of working as a team, in addition to highlighting the need for prior preparation and training by both students and facilitators for the development of activities.
\end{abstract}

Keywords: Internship and Residency, Learning and Education

\title{
INTRODUÇÃO
}

O processo do ensino-aprendizagem tem passado por diversas modificações ao longo do tempo. Variadas metodologias e formas de realizá-lo são oriundas de contextos distintos que acompanham a transformação e evolução da sociedade seja na área da saúde ou em outras áreas. A relação entre aquele que aprende e aquele que ensina perpassa cenários que vão além dos ambientes educacionais e nos fazem refletir sobre a importância dessa temática e de como tem acontecido esse processo desde suas origens até às suas repercussões mais atuais. ${ }^{1-2}$

Em meados de março de 2020, a Organização Mundial da Saúde (OMS) decretou o estado de pandemia causada pelo novo coronavírus. $\mathrm{O}$ isolamento social adotado como medida estratégica na redução de infecções fez com que o Ensino Online fosse uma alternativa das mais necessárias para a realização de atividades educativas. Esse formato de realização das atividades é caracterizado pela interação de maneira síncrona (simultânea) e assíncrona (não simultânea) e tem sido ao longo dos últimos anos evidenciado pela possibilidade de transpor barreiras físicas e aumentar a capacidade de alcance no processo educacional. $^{3}$ 
Devido às mudanças a nível mundial com relação ao uso da tecnologia, as Metodologias Ativas também têm sido alternativas para o Ensino à distância e para o modelo híbrido de ensino-aprendizagem. As propostas combinadas com Metodologias Ativas têm a vantagem de superar questões de tempo e espaço e permitem interação entre grupos. Importante destacar o papel do mediador entre as habilidades citadas que objetiva estimular a produção de conhecimento e interação, para que se encontrem diversas opiniões e buscas, minimizando a possibilidade do aluno esperar por respostas prontas a partir das perguntas realizadas e assuntos abordados. ${ }^{4}$

Os programas de Residência Multiprofissionais em Saúde têm sido cada vez mais caracterizados por seu caráter inovador que traz como proposta a formação no modelo ensinoserviço, na qual o indivíduo tem a oportunidade de construir o conhecimento a partir de uma interação entre as vertentes teórica e pratica. Esses programas são reconhecidos nacionalmente como formadores de profissionais que serão preparados para lidar com questões sociais e desafiadoras a partir de sua bagagem teórica, olhar ampliado e voltado ao trabalho em equipe, aptos a contribuir com o sistema de saúde vigente no país. Os programas se distribuem entre as mais diversas áreas da saúde, possuindo, entretanto, enfoques comuns entre as maiorias dos programas como proporcionar um ambiente adequado à reflexão crítica aonde o profissional irá cada vez mais ser capaz de contextualizar aspectos sociais, econômicos, políticos, entre outros com o contexto da saúde rompendo com o perfil profissional assistencialista, tecnicista, voltado para práticas limitadas e curativistas consequentes de formação mais tradicional. ${ }^{5}$

As discussões em torno dessa temática enfatizam a importância e necessidade da formação profissional e humana com ênfase na capacidade da reflexão crítica que permita ao indivíduo ser um agente de transformação na realidade social à qual o mesmo estiver inserido influenciando a partir de suas habilidades de uma maneira positiva. A sociedade atual marcada por um grande desenvolvimento tecnológico e rápido acesso às informações 
descaracteriza o perfil do aluno que espera pelo conhecimento trazido pelo professor. $\mathrm{O}$ acesso às informações permite com mais flexibilidade o empoderamento informativo por cada parte envolvida no processo e a partir daí tem-se uma troca, como propõem as Metodologias Ativas. ${ }^{6}$

Sendo assim, a proposta deste estudo foi a de ressaltar a importância das pesquisas nas áreas da Educação e Ensino, contribuindo e fortalecendo métodos que possam ser utilizados de forma a adaptar-se com a realidade atual promovendo um ambiente frutífero ao aprendizado. Avaliou-se como esse processo se deu em um ambiente educacional online com residentes em um programa de pós-graduação para o descobrimento, ponderação e relato das percepções com relação à temática. Baseada na perspectiva multidimensional das formas de ensino- aprendizagem e da necessidade de avaliação da percepção e de como tem sido realizado, esse trabalho objetivou então acompanhar o processo de construção, aplicabilidade e resolução das Metodologias Ativas, na disciplina intitulada como Introdução à Saúde Coletiva, oferecida para programas da Residência em Saúde Coletiva da Secretaria de Saúde do Recife- PE em meio ao contexto da pandemia causada pela COVID-19.

\section{MÉTODO}

Os dados do estudo foram extraídos de uma amostra não probabilística por conveniência composta por dez residentes do primeiro ano, do Programa de Residência em Odontologia em Saúde Coletiva da Secretaria de Saúde de Recife-PE, no ano de 2020, com participantes de uma disciplina realizada a partir do uso de metodologias ativas. Com objetivo de caracterizar a amostra e investigar o uso das metodologias ativas no ensino online, os participantes responderam a um roteiro de entrevista semiestruturado contendo (08) oito perguntas relacionadas ao conhecimento e avaliação geral da disciplina, aplicado pelo pesquisador de maneira individualizada. As perguntas se referem, respectivamente, ao conhecimento prévio do aluno acerca da metodologia utilizada, a experiência com o uso das metodologias ativas e vantagens/desvantagens com o uso dessa ferramenta de ensino. Durante 
a aplicação, cada residente foi convidado a fazer um relato livre verbal de forma resumida, sobre tais aspectos.

Este estudo foi submetido e aprovado por um Comitê de Ética em Pesquisa com Seres Humanos (CEP), sob o protocolo CAAE $\mathrm{n}^{\mathrm{o}}$ 30109420.1.0000.5569 seguindo, assim, todas as normas estabelecidas pelo Conselho Nacional de Saúde, constantes na Resolução 510/2016. Após a aprovação pelo CEP, foram apresentados aos participantes os objetivos e procedimentos da pesquisa, que posteriormente assinaram um Termo de Consentimento Livre e Esclarecido (TCLE), concordando com a sua participação na pesquisa.

$\mathrm{O}$ instrumento foi aplicado individualmente pelo pesquisador, em ambiente online, silencioso e privativo, por meio de vídeo-chamada no aplicativo ZOOM em residentes que concordaram em participar da pesquisa. O tempo médio de aplicação foi de 30 minutos por cada participante. Após a coleta e transcrição dos dados, foram realizadas as análises que serão descritas a seguir.

Após a criação do corpus textual, composto pelas entrevistas de cada participante, cada uma representando uma unidade de contexto inicial (UCI), os dados textuais foram analisados por meio do software Iramuteq (Interface de $R$ pour les Analyses Multidimensionnelles de Textes et de Questionnaires; que é ancorado no software $R$ ( $R$ Development Core Team, 2012) e na linguagem de programação python. ${ }^{7}$

Dessa maneira, a partir do Iramuteq, recorreu-se à análise de classificação hierárquica descendente (CHD). Esse procedimento classifica os segmentos de texto (ST) em consonância com seus respectivos vocabulários, com base na frequência e no $\chi^{2}$, permitindo a criação de classes de unidades de contexto elementares (UCEs), definidas tendo em vista os critérios do número de palavras analisadas e as respectivas pontuações. Esperava-se, com isso, identificar a percepção dos residentes acerca da utilização das metodologias ativas, cujos resultados são apresentados a seguir. ${ }^{8}$ 


\section{RESULTADOS}

Com relação às características pessoais, participaram do estudo oito mulheres $(\mathrm{N}=8$; $80 \%$ ) e dois homens $(\mathrm{N}=2 ; 20 \%$ ), a faixa etária média foi de 26,5 anos ( $\mathrm{DP}=2,59$, amplitude de 23 a 32 anos). Todos os participantes tinham cursado a disciplina na ocasião da coleta de dados, sendo que $60 \%(\mathrm{~N}=6)$ relataram não saber o que seriam as metodologias ativas no processo de ensino aprendizagem. Os resultados encontrados a partir da análise do corpus textual das entrevistas são dispostos na seguinte sequência: inicialmente são apresentadas as estatísticas textuais utilizadas com os participantes do estudo e, em seguida, os resultados das análises de classificação hierárquica descendente.

Os dados da estatística textual indicaram que o corpus geral foi constituído por dez textos, separados em 261 segmentos de texto (ST), com aproveitamento de 207 STs $(79,31 \%)$, o que significa que o material é representativo das análises e que há condições para a sua realização. Emergiram 9.400 ocorrências (palavras, formas ou vocábulos), sendo 1.482 palavras distintas e 775 com uma única ocorrência.

Em seguida, efetuou-se análise de CHD, por meio da qual se verificou que o corpus se dividiu em três dimensões, tendo sido descritas apenas as palavras cujos $\chi^{2}$ foram iguais ou superiores ao valor mínimo adequado $\left(\chi^{2} \geq 3,84\right)$, conforme pode ser observado no dendograma (Figura 1). A primeira dimensão é formada por uma classe proeminente que contém conteúdos relacionados ao "Trabalho em equipe" ao fazer uso das metodologias ativas (MA) - classe 5 (39 ST, 17,76\% das UCEs). A segunda é formada por duas classes, sendo que uma delas diz respeito ao "Papel do professor" - classe 3 (40 ST, 28,69\% das UCEs) e a "Reflexão crítica" a partir da experiência com o uso das MA - classe 1 (42 ST, 20,56\% das UCEs). Por fim, a terceira dimensão, também formada por duas classes, se refere respectivamente ao "Papel do estudante" - classe 2 (41 ST, 19,63\% das UCEs) e as "Vantagens/desvantagens" do uso das metodologias ativas para o ensino e aprendizagem classe 4 (45 ST, 23,36\% das UCEs). 


\begin{tabular}{|c|c|c|c|c|c|c|c|c|c|}
\hline \multicolumn{2}{|c|}{$\begin{array}{l}\text { Classe } 3 \\
\text { Papel do professor }\end{array}$} & \multicolumn{2}{|c|}{$\begin{array}{l}\text { Classe } 1 \\
\text { Reflexão crítica }\end{array}$} & \multicolumn{2}{|c|}{$\begin{array}{l}\text { Classe } 2 \\
\text { Papel do estudante }\end{array}$} & \multicolumn{2}{|c|}{ Vantagens/desvantagens } & \multicolumn{2}{|c|}{ Trabalho em equipe } \\
\hline $18,69 \%$ & & $20,56 \%$ & & $19,63 \%$ & & $23,36 \%$ & & $17,76 \%$ & \\
\hline Palavras & $\chi^{2}$ & Palavras & $\chi^{2}$ & Palavras & $\chi^{2}$ & Palavras & $\chi^{2}$ & Palavras & $\chi^{2}$ \\
\hline Acordo & 27.28 & Refletir & 21.46 & Acreditar & 17.02 & Conteúdo & 23.56 & Trabalhar & 51.09 \\
\hline Construção & 22.57 & Disciplina & 17.59 & Troca & 11.27 & Contexto & 10.12 & Dificuldade & 34.69 \\
\hline Plano & 22.14 & Objetivo & 7.54 & Conhecimento & 11.0 & Novo & 9.4 & Colega & 26.85 \\
\hline Material & 18.08 & Desenvolver & 5.0 & Vantagem & 6.68 & Aprendizado & 9.28 & Afinidade & 14.77 \\
\hline Tema & 12.97 & Informação & 4.23 & Pesquisar & 4.33 & Perder & 7.4 & Grupo & 9.32 \\
\hline Oportunidade & 12.5 & Sentido & 4.23 & Autonomia & 4.33 & Metodologia & 6.19 & Tranquilo & 6.41 \\
\hline Bom & 5.89 & Imaginar & 4.02 & Expressar & 4.16 & Ensino & 3.93 & Equipe & 6.16 \\
\hline
\end{tabular}

Figura 1. Dendrograma da classificação hierárquica descendente do corpus 


\section{DISCUSSÃO}

No que se refere à primeira dimensão, composta por uma classe, denominada trabalho em equipe, os dados apontam que essa classe se refere à adesão dos residentes em relação ao trabalho coletivo, que envolve aspectos positivos (por exemplo, "sempre gosto de trabalhar em equipe, principalmente quando temos afinidade com as pessoas"; e negativos ("eu comentei com os colegas que ao longo do contexto da pandemia parece que vem diminuindo a capacidade de trabalharmos em grupo”).

Esses resultados se assemelham a estudos que destacam prós e contras da utilização de metodologias ativas. Os estudos mostram que por um lado caracterizamse como um método motivador, aproximando o conteúdo a ser trabalhado com situações práticas e consideram a importância do desenvolvimento de capacidades como a análise e tomada de decisão, interação, comunicação, divisão de tarefas e capacidade de liderar e ser liderado. No entanto, por outro lado exigem atribuições como inteligência emocional e interpessoal, disciplina e boa gestão de tempo para realização das atividades em grupo e espírito cooperativo, sendo essas últimas competências cada vez mais exigidas pelas demandas sociais que sejam incluídas no processo de formação profissional na área da saúde. 9-10

Uma análise do conteúdo das frases da segunda dimensão, constituída pelas classes dois e quatro, associou a classe 2 - papel do estudante, à troca de conhecimento entre docentes e discentes (por exemplo, "era como se criasse um ambiente seguro para a gente expressar o que estava pensando sem nenhum julgamento de certo ou errado" e "o aluno tem a oportunidade de participar de maneira mais ativa, tanto ensinando quanto aprendendo"). Tais fragmentos sugerem que os alunos estão alertando para o fato de que as metodologias ativas de aprendizagem propiciam sua participação ativa, assim como um espaço de troca muito rico que somente é possível por meio do papel essencial destes. Esses resultados corroboram com estudo que elucida 
que a autonomia associada à liberdade valoriza a individualidade do ser e proporciona um espaço de segurança para a expressão do eu aprendiz sem barreiras. Esse processo garante o respeito e a possibilidade de aprendizagem em meio às diferenças. Encontrase na fala dos entrevistados a percepção de que o fato de terem maior autonomia permitiu que pudessem expressar diferentes concepções, de maneiras variadas sobre um tema específico para que assim, pudessem conhecer e contemplar várias faces de um mesmo objeto, o que não aconteceria se houvesse uma relativização das diferenças e uniformidade na forma de realizar as atividades. Foi unânime a concepção de que tiveram maior autonomia a partir do uso das metodologias em comparação a vivências com outros métodos tradicionais. ${ }^{11}$

Além de ter sido consenso na pesquisa quanto a se considerarem importantes para a realização da atividade é interessante destacar a relação de equilíbrio evidenciada por algumas palavras como "AUTONOMIA" e "TROCA' e que trazem para o aluno a importância de ser partícipe ativo ao mesmo tempo em que os mesmos evidenciam a troca permitindo-se serem orientados de forma leve pela figura do professor, distanciando-o da postura autoritária, detentora de todo o conhecimento e aproximandoo para um lugar de condução e auxílio na trajetória da aprendizagem. Dessa forma, essa relação não se caracteriza como apenas por transmissora unilateral, mas sim permeada pelo diálogo e participação entre mais de uma pessoa, nesse caso entre professor e aluno e alunos entre si. Vale salientar que o extremo ao proporcionar com que o aluno realizasse seu próprio aprendizado de maneira isolada e solitária não é o objetivo das metodologias utilizadas, nesse sentido se não for estabelecido com clareza o papel do professor nessa condução a vivência pode ser considerada" solta" ou "desconexa" como mencionado em parte dos relatos pelos residentes. ${ }^{1}$ 
Tal qual a segunda classe, com a qual compartilha conteúdo, a classe 4 nomeada vantagem/desvantagem denota a priorização desse tipo de metodologia no currículo acadêmico. Portanto, alguns dos fragmentos versam o que foi percebido (por exemplo, "Ela é muito mais eficaz em qualquer contexto do que a metodologia tradicional") e de ampliação das experiências anteriores (por exemplo, "Eu considero importante também às percepções anteriores, pois de onde você vem e tudo o que estudou contribui para a sua formação”). Em relação ao primeiro aspecto alguns autores revelam que a metodologia tradicional não tem sido mais adequada às necessidades atuais da sociedade e ao processo de educação em si por apresentar apresentarem diversas fragilidades. ${ }^{2-12-13}$ Considerar que o professor é um transmissor de informação e o aluno receptor encontra-se como formato obsoleto dentro da educação e as metodologias ativas buscam, apesar de ainda encontrarem desafios, justamente romper com as limitações e efeitos indesejados do método tradicional. ${ }^{14}$

No que diz respeito à ampliação das experiências anteriores dos alunos, é possível identificar a importância de maneira geral da bagagem de informações e conhecimento prévios por parte do aluno para esses momentos vivenciados a cada encontro da disciplina. Um dos pilares da andragogia (educação para adultos) é conhecido como justamente esse arcabouço teórico e prático vivenciado pelo profissional tanto em outras vivências de aprendizagem assim como frente às situações experimentadas ao longo de sua vida. ${ }^{15}$

Esse fator é ainda mais potencializado frente à realidade atual pelo acesso promovido pelas tecnologias à informação e ao conhecimento com muita facilidade e em pouco tempo. A questão seria como então aplicar toda essa quantidade de informações e conhecimento em situações cotidianas de trabalho que desafiam esse 
profissional a agir de forma reflexiva e ativa colocando em prática o seu conhecimento técnico-científico.

Por fim, a terceira dimensão é composta pelas classes um e três, intituladas reflexão crítica e papel do professor, respectivamente. Na classe 1, destacam-se aspectos voltados ao autoconhecimento e aprendizado pessoal dos alunos (por exemplo, "eu fazia a disciplina com prazer, pois refletia diante do que a professora pediu e construía o meu conhecimento" e "a gente precisa refletir e confrontar com outros conhecimentos e informações que vemos no dia a dia”). Esses resultados também são encontrados em outros estudos que discutem sobre as vivências experimentadas em ambientes educacionais serem compatíveis com a realidade atual proporcionando uma melhor visão de mundo, tornando o aprendizado interessante e prazeroso, além de desencadear gatilhos reflexivos frente às problemáticas da vida de maneira positiva. ${ }^{2-16}$ A reflexão crítica é o catalisador para que o conhecimento teórico possa ser atrelado à prática e a associação entre a informação e como os profissionais utilizarão esse conhecimento se encontrem para fazer sentido no cotidiano e dia a dia de trabalho. ${ }^{6}$

A classe 3 - papel do professor aponta para o fato de que este propiciou a expressão verbal e autonomia dos discentes (por exemplo, "nós tivemos a oportunidade de poder falar um pouco sobre o que estava se propondo a fazer" e "a professor nos deu autonomia de buscar outros materiais e formular as apresentações do jeito que a gente quisesse"). A respeito disso outros pesquisadores advertem que cabe ao professor despertar a atenção e interesse, sensibilizar o aluno em suas capacidades, ser entendidos por este e levá-lo à expressão e ao diálogo, além estimular a produção de conhecimento e interação, para que se encontrem diversas opiniões e buscas, minimizando a possibilidade do aluno esperar por respostas prontas a partir das perguntas realizadas e 
assuntos abordados e não estar somente preocupado em expor o tema a ser trabalhado e seu conhecimento sobre este. ${ }^{17-18}$

É necessário, ainda, que em sua prática pedagógica, ele trabalhe vários aspectos do aluno, como a sua afetividade, suas percepções, sua expressão, seus sentidos, suas críticas, individualidade e sua criatividade. No entanto, isso não significa que práticas pedagógicas que ressaltem tais habilidades dependam somente do professor para serem intencionais. ${ }^{19}$

A condição de reflexão no processo de aprendizagem se torna essencial e é um dos pontos mais interessantes com relação a esse tipo de estudo. Na classificação, essa classe aparece associada à classe que remete ao papel do professor, o que indica a relação entre a possibilidade de criação de um ambiente reflexivo de acordo com a postura daquele estaria na posição de condução. Sendo assim quanto maior possibilidade de ampliação de espaço para reflexão permitido pelo profissional educador mais evidente a potencialização dos momentos de imaginação, ponderação e capacidade de postura ativa crítica-reflexiva desenvolvida frente às atividades propostas da disciplina. Esse movimento desconstrói a ideia da criação de um perfil de aluno que simplesmente espera pela ação de trazer o conteúdo partindo do professor. Para isso é necessária a reflexão constante sobre a preparação prévia desse profissional. ${ }^{20}$

Alguns estudos demonstram somente possuir o conhecimento teórico-técnico não seriam suficientes sem o conhecimento relacionado a didáticas as quais deveriam ser aplicadas, nos momentos de formação desde a criação de objetivos de aprendizagem, planos de aula e escolha das metodologias a serem utilizadas. Ressalta-se a necessidade da formação do profissional contínua do educador com relação ao propósito das ferramentas a serem utilizadas mediante preparação e capacitação em paralelo ao aprofundamento com o conteúdo técnico da área profissional a ser considerada na área 
do Ensino $_{2}$ incluindo a oportunização para reajustes necessários de acordo com as diferentes realidades e contextos. ${ }^{21-22}$

Uma das limitações mencionadas pelos residentes com relação aos momentos foi o fato de a interação ter acontecido somente online em comparação com a vivência presencial e, além disso, a importância da preparação do professor para a condução da disciplina em si deixando claros as orientações e comandos para realização das atividades. A dinamização com relação ao tipo de metodologia também fez parte de alguns discursos. Alguns mencionaram que a repetição de algumas ferramentas torna desinteressantes os momentos vivenciados.

\section{CONCLUSÂO}

Segundo as informações obtidas pelos relatos dos residentes a utilização de metodologias ativas de maneira oportuna e sendo pensada de forma a potencializar os objetivos de aprendizagem a serem abordados possibilita que o processo aconteça de forma mais eficaz e com significado para todos os componentes ainda que no formato online.

A possibilidade de que esse fluxo seja permeado pela troca sem estar centrado no sujeito que aprende ou no sujeito que ensina, levando em consideração o contexto social no qual estão inseridos ambos e a sua capacidade de reflexão e contribuição faz parte de uma teoria mais construtivista que destaca características constituintes e colaboradoras para um processo formativo e de ensino-aprendizagem transformador.

Ainda com relação à caracterização da percepção dos residentes realizada nessa pesquisa destaca-se a importância da utilização das Metodologias Ativas de Ensino e aprendizagem como estimuladora do romper com o ensino tradicional e o estímulo a formação de profissionais autônomos, com capacidade de reflexão crítica e a 
possibilidade de transformação da realidade por meio da implicação do conhecimento na realização da prática.

Considera-se importante mediante as considerações analisadas a formação contínua na área da docência daquele que possui o papel de facilitador para que possa alem dos conhecimentos técnicos interagir de forma a proporcionar um ambiente para o processo de ensino-aprendizagem dialógico, amplo, que favoreça a expressão individual de cada um e seja permeado pela troca entre todos.

\section{REFERÊNCIAS}

1. Borges TS, Alencar G. Metodologias ativas na promoção da formação crítica do estudante do ensino superior. Cairu em Revista, Cairu, 2014; 3(4): 119-143.

2. Paiva MRF, Parente JRF, Brandão IR, Queiroz AHB. Metodologias Ativas De Ensino-Aprendizagem: Revisão Integrativa. Sanare- Rev. de Políticas Públicas, Sobral (CE), 2016; 15(2): 145-156.

3. Oliveira KS, Cardoso PHG, Santos LC. Possibilidades e desafios da educação à distância em tempos de pandemia da covid-19. Anais VII CONEDU - Edição Online Campina Grande: Realize Editora, 2020.

4. Clementino A, Souza CSM, Hito SC. Metodologias Ativas como facilitadora da construção do conhecimento no Ensino Superior EAD. Investigação Científica. No prelo 2017.

5. Silva JC, Contim D, Ohl RIB, Chavaglia SRR, Amaral SEM. Percepção dos residentes sobre sua atuação no programa de residência multiprofissional. Acta Paulista de Enfermagem, 2015; 28(2), 132-138. 
6. Prado ML, Velho MB, Espínola DS, Sobrinho SH, Backes VMS. Arco de Charles Maguerez: refletindo estratégias de metodologia ativa na formação de profissionais de saúde. Esc. Anna Nery (impr.) 2012 jan-mar; 16 (1): 172-177.

7. Ratinaud, P. Iramuteq: Interface de R pour les Analyses Multidimensionnelles de Textes et de Questionnaires [Computer software]. 2009. Disponível em http://www.iramuteq.org

8. Camargo, BV, Justo AM. Tutorial para uso do software de análise textual Iramuteq. Laccos, 2013; Brasil: UFSC.

9. Rocha EF. Metodologias Ativas: um desafio além das quatro paredes da sala de aula.2014.Disponívelem:http://www.abed.org.br/arquivos/Metodologias_Ativas_ale m_da_sala_de_aula_Enilton_Rocha.pdf

10. Negro-Dellacqua M, Junior PMC, Sá-Junior AR, Borlotto T, Costa FV, Souza IF. Potencialidades e desafios na aplicação de metodologias ativas no ensino de Fisioterapia: visão discente. Res. Soc. Dev. 2019; 8(5): e32851022

11. Teófilo TJS, Dias MSA. Concepções de docentes e discentes acerca de metodologias de ensino-aprendizagem: análise do caso do Curso de Enfermagem da Universidade Estadual Vale do Acaraú em Sobral - Ceará. Interface - Comunic., Saúde, Educ., 2009; 13(30); 137-51.

12. Colares KTP, Oliveira W. Metodologias Ativas na formação profissional em saúde: uma revisão. Revista Sustinere, 2019; 6(2); 300 - 320

13. Soares SS, Silva NC, Moncaio ACS. Metodologias Ativas no Ensino Superior: opiniões, conhecimentos e atitudes docentes. J Nurs UFPE online, Recife, 2019; 13(3): 783-95.

14. Mello CCB, Alves RO, Lemos SMA. Metodologias de ensino e formação na área da saúde: revisão de literatura. Rev. CEFAC. 2014 Nov-Dez; 16(6). 
15. Dranagov PB, Friedlander MR, Sanna MC. Andragogia na saúde: estudo bibliométrico. Esc. Anna Nery, Rio de Janeiro; Mar.2011; 15(1): 149-156.

16. Dorigon T, Romanowski JP. Revista Intersaberes, Curitiba, jan/jul 2008; ano 3, n. 5, p. $8-22$.

17. Sgariboldi AR, Pugina ACG, Silva MJP. Análise da percepção dos professores em relação aos sentimentos dos alunos em sala de aula. Rev. esc. enferm. USP, São Paulo, out. 2011; 45(5): 1206-1212.

18. Clementino A, Souza CSM, Hito SC. Metodologias Ativas como facilitadora da construção do conhecimento no Ensino Superior EAD. Investigação Científica. No prelo 2017.

19. Abed ALZ. O desenvolvimento das habilidades socioemocionais como caminho para a aprendizagem e o sucesso escolar de alunos da educação básica. Constr. psicopedag., São Paulo,2016;24(25):8-2.

20. Diesel A, Marchesan MR, Martins SN. Metodologias Ativas de ensino na sala de aula: um olhar de docentes da educação profissional técnica de nível médio. Rev. Signos, Lajeado, 2016. 37(1): 153-169.

21. Paranhos VD, Mendes MMR. Currículo por competência e metodologia ativa: percepção de estudantes de enfermagem. Revista Latino-Americana De Enfermagem, 2010. 18(1), 109-115. $\quad$ https://doi.org/10.1590/S0104$\underline{11692010000100017}$

22. Freitas, Daniel Antunes et al. Saberes docentes sobre processo ensino-aprendizagem e sua importância para a formação profissional em saúde. Interface - Comunicação, Saúde, Educação [online]. 2016, v. 20, n. 57 